\title{
Haematological complications of therapy with pyrimidine analogues
}

\author{
C. G. GeARY \\ Department of Haematology, United Manchester Hospitals, Manchester M139WL
}

Pyrimidine analogues produce their effects by inhibiting nucleic acid synthesis and inevitably damage tissues with high rates of cell turnover. These are the bone marrow, gastro-intestinal epithelium, and, to a lesser extent, renal and hepatic parenchyma and skin. The haematologist who treats a case of acute leukaemia with cytosine arabinoside is, of course, attempting ablation of the leukaemic marrow; the rationale of this therapy presupposes the existence of residual normal haemopoietic stem cells, which are capable of repopulating the marrow (Killmann, 1970). In this situation moderate or severe hypoplasia of the bone marrow is an inevitable prelude to remission of the disease (Bailey et al., 1971).

In the treatment of viral infections with pyrimidine analogues, on the other hand, the haematological side-effects are incidental though none the less hazardous. However, the functional reserve of normal marrow is considerable. Haemopoietic cell-lines can be considered divided into three compartments: stem cells, maturing ('committed') cells, and functional cells (Fig. 1). Proliferation occurs, albeit slowly, in the stem-cell compartment, which has the dual role of self-maintenace and of providing cells for the maturation pathway: their numbers and proliferation rates are under homeostatic control. Proliferation is also occurring amongst the earlier

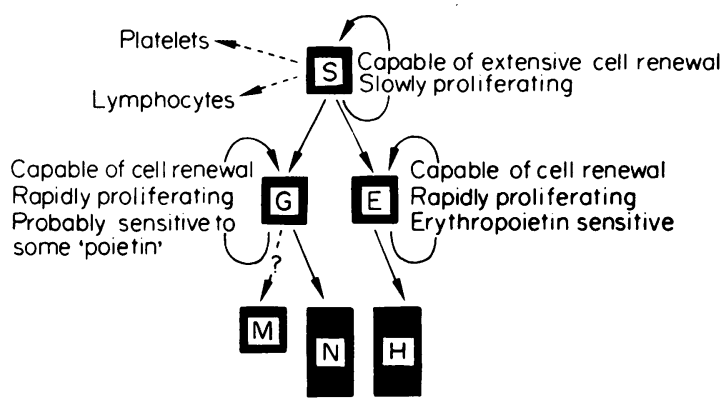

FIG. 1. The functional 'compartments' of the normal bone marrow. Reproduced by permission from Frederick Stohlman (Ed.). Hematopoietic stem cell compartment: Patterns of differentiation following radiation or cyclophosphamide. By Samuel Hellman, Helen E. Grate, John T. Chaffey and Richard Carmel. In: Haemopoietic Cell Proliferation (1970). Grune and Stratton, New York. members of the maturing cell compartment. In the normal marrow, events in this compartment dominate the proliferative characteristics of the tissue (Lamerton \& Steel, 1968; Lamerton, 1972).

It has been demonstrated in experimental animals that stem cells account for only about $1 \%$, or less, of the proliferating cells present in the marrow; the remainder are in the maturing compartment, which are also dividing much more rapidly (Lahiri \& van Putten, 1969). The rate of production of mature erythrocytes, granulocytes and platelets depends on the intermitotic time of the dividing cells; in the maturing compartment this is probably a matter of hours, whereas in the stem-cell compartment, divisions occur much less frequently. Thus, in the marrow, there is a small, normally slowly dividing stem-cell compartment and a much larger and rapidly-dividing population of later committed precursors.

The capacity of the marrow to withstand damage by cytotoxic drugs depends on two critical factors: (1) the speed with which the stem-cell population can regenerate following death of more mature cells and (2) the number of stem cells required.

Pyrimidine analogues are 'phase-specific' drugs, that is, they act only on replicating cells during the S-phase of the cycle. They appear to have no effect on stem cells, or on 'resting cells' (in $G_{0}$ ). Since the dividing cells are not in synchrony, but are entering S-phase at different times, it has been held that the cytotoxic action of these drugs is enhanced if given as a slow continuous infusion: there is some support from haematological practice that this is so (Ellison et al., 1968).

In rats, it has been shown that, following obliteration of all recognizable granulocyte and erythroblast precursor cells with methotrexate, the stem-cell population re-establishes haemopoietic function so rapidly that red cell and granulocyte production are back to $50 \%$ of their normal values $3 \frac{1}{2}$ and 6 days, respectively, after the production of aplasia (Blackett, 1968). In man, regeneration is slower, but it is important to realize that in aplasia produced by pyrimidine analogues, recovery can be expected if the patient has normal marrow reserve and can be protected during the aplastic phase. The situation is thus different from that in idiopathic aplasia, or that 
due to some drugs, in which concomitant damage to the microvasculature of the marrow, possibly mediated by an immunological mechanism, delays or prevents recovery. On the other hand, patients with reduced marrow function may suffer prolonged hypoplasia. These include the elderly, those with malignant haematological disorders, hepatic or renal disease, overwhelming toxaemia or previous malnutrition.

\section{Therapy with IDU and Ara-C}

There are now a number of reports of treatment of viral infections with systemic pyrimidine analogues. Haematological side-effects have been variable and apparently unpredictable: thus Nolan and his colleagues reported troublesome leucopenia and thrombocytopenia after the use of IDU (Nolan, Carruthers \& Lever, 1970). On the other hand, JuelJensen (1971) treated five cases of disseminated herpetic infection with Ara-C at a dosage of $2 \mathrm{mg} / \mathrm{kg}$ body weight without any signs of marrow depression, and Longson reported no haematological side-effects in patients treated with IDU at a dosage of $100 \mathrm{mg} / \mathrm{kg}$ body weight.

TABLe 1. Side-effects of IDU and Ara-C

\begin{tabular}{ll}
\hline \multicolumn{1}{c}{ IDU } & \multicolumn{1}{c}{ Ara-C } \\
\hline Pancytopenia & Megaloblastosis \\
Aplastic anaemia & Thrombocytopenia \\
Stomatitis & Pancytopenia \\
Enteritis & Aplastic anaemia \\
Alopecia & Immunosuppression \\
Nail loss & Gastro-intestinal disturbance \\
Chromosomal changes (?) & Renal and hepatic damage \\
& Fever \\
& Rashes \\
& Chromosomal changes (?) \\
\hline
\end{tabular}

Figures 2 and 3 represent the haematological progress of two haematologically normal patients treated, respectively, with Ara-C and IDU. The onset of marrow depression is not usually noted until about the seventh day; it is usual to give pyrimidine analogues in 'pulses' over 3-5 days, and the pancytopenia may not appear until after the drug has been withdrawn. Thrombocytopenia is often the first sign of marrow damage, though examination of the marrow will show toxic changes much earlier; for example striking megaloblastosis is a feature of treatment with Ara-C, and develops within hours. Marrow aspiration later will show hypoplasia or aplasia; thus in the patient illustrated in Fig. 1, the marrow was completely aplastic at Day 14 . The extent of myeloid depression is best assessed by marrow aspiration; the peripheral blood count may be misleading.

Calabresi (1965) attempted regional protection of

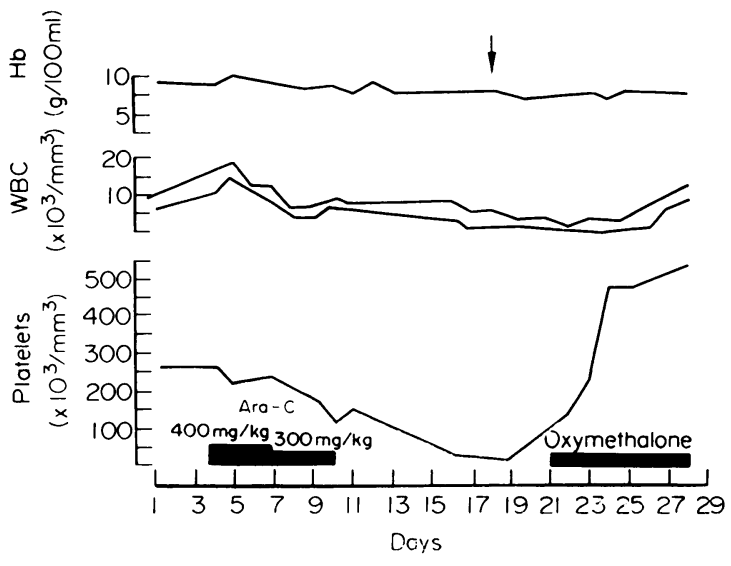

FIg. 2. A man aged 40 was treated with cytosine arabinoside for herpes simplex encephalitis. At the point indicated by the arrow, the marrow was severely hypoplastic. It is likely that spontaneous recovery would have occurred without oxymethalone therapy.

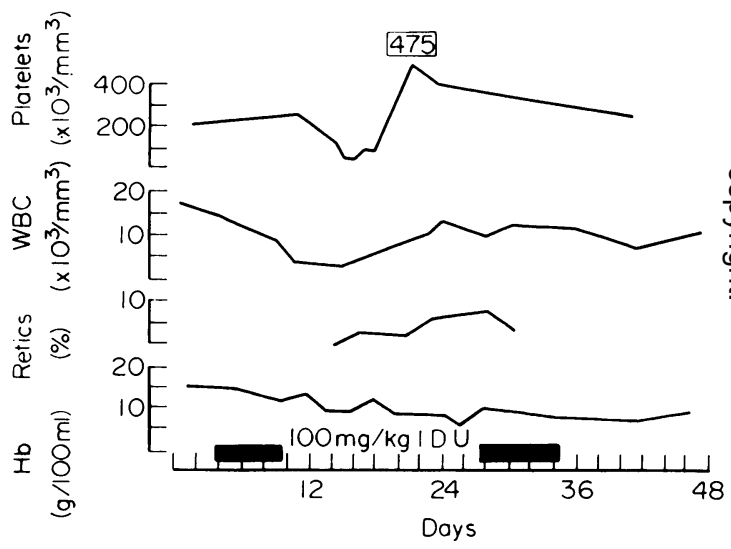

FIG. 3. A child of 2 received IDU for treatment of disseminated herpes simplex. Transient marrow depression recovered when the drug was discontinued and did not recur following a second course.

femoral marrow in patients with malignant disorders undergoing treatment of viral infections with IDU; intra-arterial infusions of thymidine appeared to preserve some haemopoietic function in this site. It is interesting that second courses of the analogue seem to cause less marrow depression than the first (Fig. 2).

\section{The hypoplastic phase}

Once severe marrow hypoplasia is established, therapy with the analogue must be stopped. Withdrawal of the drug may be sufficient, but a prolonged aplastic episode is a serious complication, even though eventual marrow recovery can be expected. 
The risks are of thrombocytopenic bleeding, particularly cerebral haemorrhage, and septicaemia. Serious haemorrhage is rarely a risk with a platelet count of more than $20,000 / \mathrm{mm}^{3}$ (Editorial, 1972). When haemorrhage occurs it is best treated by fresh blood and, if possible, platelet transfusions. Six platelet concentrates are given, repeated $12 \mathrm{hr}$ later if no clinical response is evident. Improvement may be monitored by the platelet count and bleeding time. Infection often exacerbates thrombocytopenic bleeding and requires vigorous treatment. A neutrophil count of less than $250 / \mathrm{mm}^{3}$ for more than 2 or 3 days is an ominous sign; Gram-negative septicaemia and secondary fungal infections are definite risks. Blood cultures, naso-pharyngeal, sputum, urine and perineal swabs should be taken, and the patient barrier-nursed in a side ward. In patients with profound neutropenia, Gram-negative septicaemia is probably best treated with a combination of intravenous carbenicillin and cephaloridine; gentamicin seems to be less effective in the absence of functioning granulocytes.

A bowel sterilization programme, using broadspectrum antibiotics and an anti-fungal agent, has been advocated in patients with agranulocytosis; early reports suggest that this regimen is more effective if the patient is isolated in a plastic 'lifeisland' or a laminar air flow system (van der Weyden \& Firkin, 1972). Leucocyte infusions are now a practical proposition in centres where IBM cell separators are available, and may be of value in the presence of septicaemia or infections not responsive to antibiotics.

Anaemia will eventually occur if the aplasia is prolonged or if accompanied by thrombocytopenic bleeding; it is best treated by packed cells or fresh blood if there is profound thrombocytopenia.

\section{Steroid therapy}

Prednisolone is often given to patients with amegakaryocytic thrombocytopenia but it is of doubtful value; in patients with severe neutropenia, it may increase the risks of infection and would possibly be undesirable in patients with disseminated viral infections. The androgen derivative, oxymethalone, is however, effective in approximately $50 \%$ of cases of aplastic anaemia, and should be administered in any case in which aplasia is prolonged (Sanchez-Medal et al., 1969). It appears to be more effective in stimulating erythropoiesis than leucopoiesis or thrombopoiesis, but the clinical manifestations of bleeding usually disappear in those patients responding to the drug.

\section{References}

Bailey, C. G., Geary, C. G., Israels, M. C. G., Whittaker, J. A., Brown, M. J. \& Weatherall, D. J. (1971) Cytosine arabinoside in the treatment of acute myeloblastic leukaemia. Lancet, i, 1268.

BLACKETT, N. M. (1968) Investigation of bone marrow stem cell proliferation in normal, anaemic and irradiated rats, using methotrexate and tritiated thymidine. Journal of National Cancer Institute, 41, 909.

Calabresi, P. (1965) Clinical studies with systemic administration of antimetabolites of pyrimidine nucleosides in viral infections. Annals of the New York Academy of Sciences, 130, 192.

EdITORIAL (1972) Platelets for Transfusion. Lancet, i, 25.

Ellison, R. R., Holland, J. F., Weil, M., Jacquilat, C., Boiron, M., Bernard, J., Sawitsky, A., Rosner, F., Gussof, B., Silver, R. T., Karanas, A., Cuttner, J., Spurr, C. L., Hayes, D. M., Blom, J., Leone, L. A., Hanrani, F., Kyle, R., Hutchinson, J. L., Forcier, R J. \& Moon, J. H. (1968) Arabinosyl cytosine: a useful agent in the treatment of acute leukaemia in adults. Blood, 32, 507.

Juel-Jensen, B. E. (1971) Anti-viral chemotherapy in patients with severe infections with herpes simplex and varicella zoster virus, including infections in cases with malignant disease and those on immuno suppressant drugs. In: Proceedings of the XIII European Symposium on Poliomyelitis and Other Virus Diseases (Helsinki). Acta medica belgica, Brussels.

Killmann, S-A. (1970) In: Haemopoietic Cell Proliferation (Ed. by F. Stohlman), p. 267. Grune \& Stratton, New York.

Lamerton, L. F. \& Steel, G. G. (1968) Cell population kinetics in normal and malignant tissues. In: Progress in Biophysics and Molecular Biology (Ed. by J. A. V. Butler and D. Noble), 18, 247-283. Pergamon Press, Oxford.

LAMERTON, L. F. (1972) Cell proliferation and the differential response of normal and malignant tissues. British Journal of Radiology, 45, 161.

LahiRI, S. K. \& Van Putten, L. M. (1969) Distribution and multiplication of colony forming units from bone marrow and spleen after injection in irradiated mice. Cell and Tissue Kinetics, 2, 21.

LONGSON, M. Personal communication.

Nolan, D. C., Carruthers, M. M. \& Lever, A. M. (1970) Herpes virus hominis encephalitis: thirteen cases, six treated with idoxuridine. New England Journal of Medicine, 282, 10.

Sanchez-Medal, L., Gomez-Leal, A., Duarte, L. \& Rico, M. G. (1969) Anabolic androgenic steroids in the treatment of acquired aplastic anaemia. Blood, 34, 283.

VAN DER WEYDEN, M. \& Firkin, B. G. (1972) The management of aplastic anaemia in adults. British Journal of Haematology, 22, 1. 